\title{
Evaluation of Fillers Dispersion Degree in Elastomeric Magnetic Composites
}

\author{
Ján Kruželák, ${ }^{1}$ Sybill Ilisch, ${ }^{2}$ Ivan Hudec, ${ }^{1}$ and Rastislav Dosoudil ${ }^{3}$ \\ ${ }^{1}$ Department of Plastics and Rubber, Institute of Polymer Materials, Faculty of Chemical and Food Technology, \\ Slovak University of Technology, Radlinského 9, 81237 Bratislava, Slovakia \\ ${ }^{2}$ Center of Engineering Sciences, Martin Luther University, Halle-Wittenberg, D06099 Halle, Germany \\ ${ }^{3}$ Department of Electromagnetic Theory, Faculty of Electrical Engineering and Information Technology, \\ Slovak University of Technology, Il'kovičova 3, 81219 Bratislava, Slovakia
}

Correspondence should be addressed to Ján Kruželák, jan.kruzelak@stuba.sk

Received 8 November 2011; Accepted 19 April 2012

Academic Editor: Sontipee Aimmanee

Copyright (C) 2012 Ján Kruželák et al. This is an open access article distributed under the Creative Commons Attribution License, which permits unrestricted use, distribution, and reproduction in any medium, provided the original work is properly cited.

\begin{abstract}
Elastomeric magnetic composites were prepared by incorporation of strontium ferrite into polymer matrices based on natural as well as butadiene rubber. Besides the rubber and ferrite, or the combinations of ferrite and carbon black (in case of natural rubber), the model rubber compounds contained only ingredients which support curing process. The study was dedicated to the observation of fillers dispersion degree in the rubber matrices and investigation of physical-mechanical and magnetic properties of prepared composites. The results indicate that the dispersion degree of ferrite in the rubber matrices is not very high, but it can be positively influenced by the addition of carbon black. Despite of the fact that ferrite exhibits only low reinforcing effect on cross-linked elastomeric materials, physical-mechanical properties can be also positively influenced by the mutual change in combinations of both fillers (ferrite and carbon black). The prepared materials seem to have suitable magnetic and elastic properties.
\end{abstract}

\section{Introduction}

In the recent years, a rapid interest in development of smart materials consisting of rubber matrix and magnetic active particles has been shown [1-4]. The final properties of elastomeric magnetic composites are strongly dependent on the characteristics of polymer matrix especially. However, by integration of magnetic materials, new properties and technological abilities can be provided. The advantage of such type of materials is that their properties can be modified for the requirements of specific applications. Because of their elasticity and easy mouldability, they are suitable for additive devices, where elasticity and flexibility are additional and important parameters. Moreover, they have very good magnetic properties. Rubber magnets can absorb shock and sound, so they can be applied in dc motors, motor parts, memo holders, intelligent tyres, microwave and radar technology, and also in other technological applications.
The quality of rubber blends to a large extent depends on the ability of filler or fillers to be well dispersed in the rubber matrix. The mixing process can be characterized by two essential elements of mixing process: the distributive and the dispersion mixing. The distributive mixing ensures the homogenous concentration of ingredients in all rubber volume. The dispersion mixing ensures the dispersion of filler into primary particles or aggregates. The quality of rubber blends, mainly physical properties, depends also on the quality of phases interface, stress on interface, and chemical or physical compatibility of components on interface. Moreover, the size of the dispersed phase domains is also very important. In general, the smaller the filler particles are, the better properties of final rubber blends are possible to observe. Thus, if we want to achieve suitable mechanical properties of rubber materials, it is very important to ensure good homogeneity of immixture and the best possible dispersion of ingredients [5]. 
TABLE 1: Composition of rubber blends filled only with ferrite.

\begin{tabular}{lcccccc}
\hline Component & Rubber & ZnO & Stearin & CBS & Sulfur & Filler \\
\hline Content, phr & 100 & 3 & 2 & 1.5 & 1.3 & $0-100$ \\
\hline
\end{tabular}

TABLE 2: Composition of rubber blends filled with fillers combinations.

\begin{tabular}{lcccccc}
\hline Component & Rubber & ZnO & Stearin & CBS & Sulfur & Fillers \\
\hline Content, phr & 100 & 5 & 1.5 & 1.5 & 1.3 & 85 \\
\hline
\end{tabular}

TABLE 3: Characteristics of strontium ferrite.

\begin{tabular}{lc}
\hline Characteristics & Values \\
\hline Density $\rho, \mathrm{g} \cdot \mathrm{cm}^{-3}$ & 4.73 \\
Specific surface area, $\mathrm{m}^{2} \cdot \mathrm{g}^{-1}$ & 4.06 \\
Total porosity, \% & 55.62 \\
Coercivity, $\mathrm{kA} \cdot \mathrm{m}^{-1}$ & 117 \\
Remanent magnetic induction, $\mathrm{T}$ & 0.170 \\
\hline
\end{tabular}

The goal of the work was to investigate the filler dispersion degree in the rubber blends filled with magnetic filler as well as in the rubber systems filled with combinations of ferrite and carbon black. The microstructure observation of prepared materials and mechanical properties is then described.

\section{Experimental}

The preparation of elastomeric magnetic composites was carried out in the laboratory mixer Brabender in two mixing steps. In the first step, the rubber and the filler were compounded $\left(9 \mathrm{~min}, 90^{\circ} \mathrm{C}\right)$, in the second step $(4 \mathrm{~min}$, $90^{\circ} \mathrm{C}$ ), the curing system was added. The curing process was performed at $150^{\circ} \mathrm{C}$ for the optimum cure time under a pressure of approximately $20 \mathrm{MPa}$ by using the hydraulic press Fontune.

Rubber systems filled only with magnetic filler were prepared by incorporation of strontium ferrite $\mathrm{SrFe}_{12} \mathrm{O}_{19}$, type FD8/24 (Magnety a.s., Světlá Hora, Czech Republic), in rubber matrices based on natural (SMR 20, Mardec, Malaysia) as well as highly cis-1,4 butadiene rubber (Buna CB 24, Lanxess, Germany). In order to prepare rubber materials filled with combinations of carbon black and ferrite, the carbon black batch of natural rubber (Elastorsa, Slovakia) was used. Besides rubber and fillers, the model rubber compounds contained only ingredients, which support curing process. The content of these additives was the same in all rubber compounds (Tables 1 and 2). The content of ferrite in rubber blends filled only with magnetic filler was changed in range from 0 to 100 phr. The total content of fillers in rubber compounds filled with combinations of ferrite and carbon black was kept constant $85 \mathrm{phr}$, and only the weight fraction of ferrite in the combinations of both fillers $\left(w_{f}=\right.$ $\mathrm{mF} /(\mathrm{mF}+\mathrm{mCB}))$ was changed. The characteristics of applied ferrite are mentioned in Table 3.

Optical microscopy was used to characterize the filler dispersion. We made gloss cuts by cutting stretched samples having the size of $1 \times 5 \times 20 \mathrm{~mm}$ by a razor blade at room temperature and examined the cut surfaces by optical microscope LEICA QWin Imaging Systems, Ltd. If the surface of the cut contains filler agglomerate or aggregates, the light scatters at this place, and its area appears dark. With an image analysis program, one can calculate the area of visible filler regions according to ASTM D 2663-69. The degree of the macrodispersion was assessed as the amount of the nondispersed agglomerates with an average diameter larger than $5 \mu \mathrm{m}$. From every sample, six pictures were taken and from every picture, six image analyses were carried out [6].

The microstructure of the samples was observed using the scanning electron microscope TESLA BS 300 with digitizing unit Tescan equipped with Wintip software. The samples were first cooled down in liquid nitrogen and subsequently fractured into small pieces with surface area of $3 \times 2 \mathrm{~mm}$. Each surface was coated with a thin layer of gold and placed into the SEM.

Rheological properties of the prepared rubber blends were investigated using RPA 2000. The samples were analyzed under strain amplitude from 0.15 to $700 \%$ at a constant frequency of $0.2 \mathrm{~Hz}$ and temperature $80^{\circ} \mathrm{C}$.

Tensile properties were performed on the TIRATEST equipment at an initial distance of pneumatic heads equal to $80 \mathrm{~mm}$ and a deformation velocity of $500 \mathrm{~min} \cdot \mathrm{min}^{-1}$. The test pieces were dumbbell shaped (width $6.4 \mathrm{~mm}$, length $25 \mathrm{~mm}$, and thickness $2 \mathrm{~mm}$ ). The average of 5 tests is reported here.

Magnetic properties of composites on the magnetometer TVM-1 at room temperature were determined. The basic principle of measurement is induction method of scanning of scattering magnetic flux $\phi$ induced by magnetic vibrating sample.

\section{Results and Discussion}

The degree of dispersion and the uniform distribution of fillers applied in rubber matrices are essential for rubber compounds to achieve adequate properties of cured composites. Optical microscopy enables the quantitative evaluation of materials structure-the shape and the dimension of phases present in materials structure. The values of the strontium ferrite dispersion degree in blends based on natural as well as butadiene rubber are shown in Figures 1 and 2.

From Figure 1, it becomes evident that the dispersion degree of ferrite in natural rubber-based blends increases 


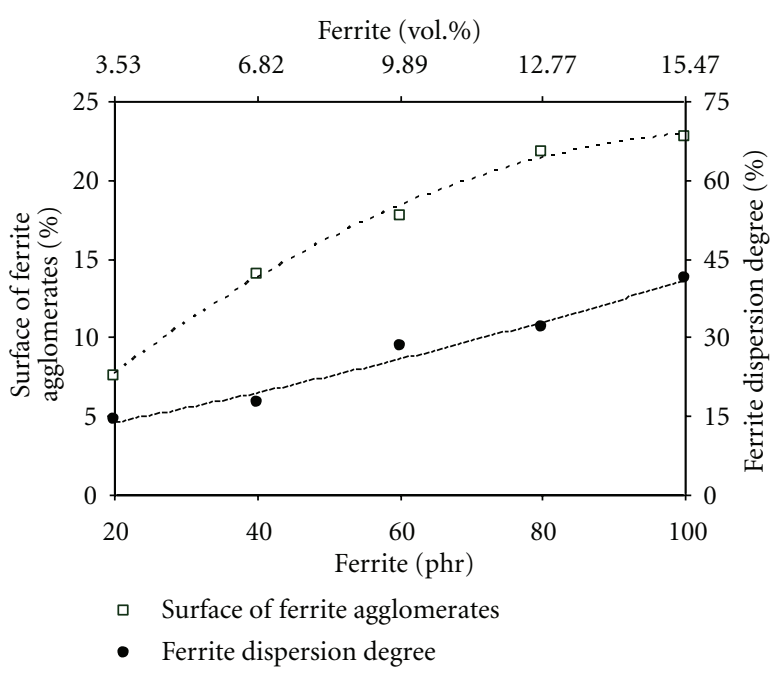

FIGURE 1: Influence of ferrite content on ferrite dispersion degree and surface of ferrite agglomerates in natural rubber-based blends.

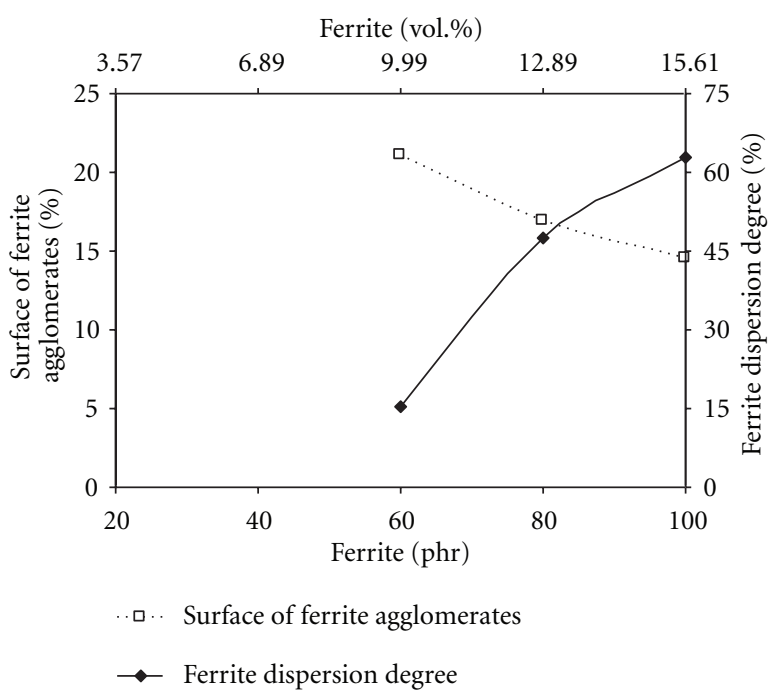

Figure 2: Influence of ferrite content on ferrite dispersion degree and surface of ferrite agglomerates in butadiene rubber-based blends.

with the increase in loadings, although at the maximum ferrite content the value of dispersion degree was only about $40 \%$. This is likely attributed to the formation of aggregates and agglomerates of applied filler; the total surface of aggregates and agglomerates also increases with increasing content of magnetic filler (Figure 1). The increasing tendency of the ferrite dispersion degree in dependence on the filler content was demonstrated also in case BR-blends (Figure 2). The ferrite dispersion degree in butadiene rubber based blends with higher filler content $(80,100 \mathrm{phr})$ was higher in comparison with NR-blends with equivalent ferrite content. The total surface of filler aggregates and agglomerates in butadiene rubber was found to decrease with doping content (Figure 2).

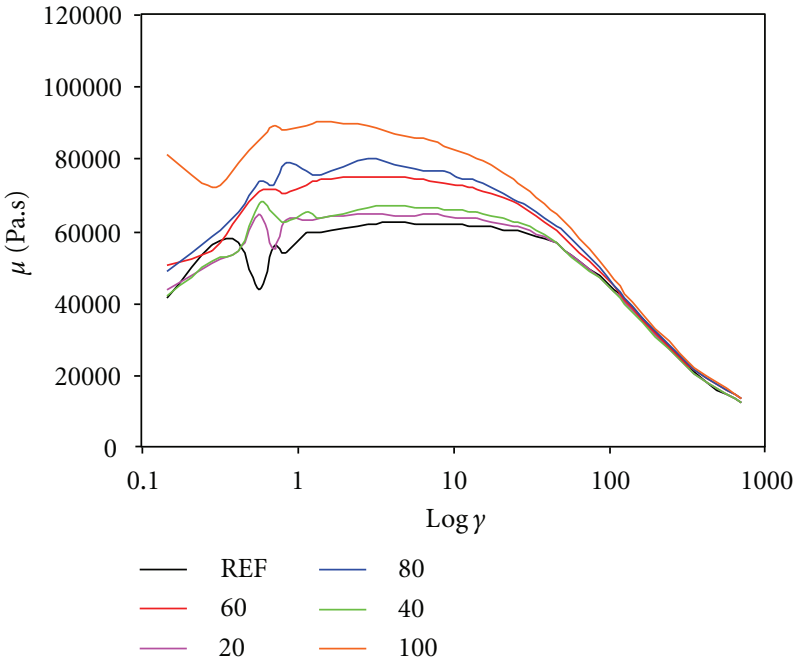

FIGURE 3: Dependence of dynamic viscosity $\mu$ of natural rubberbased blends filled with different content of ferrite on strain amplitude $\gamma$ at temperature $80^{\circ} \mathrm{C}$ and frequency $0.2 \mathrm{~Hz}$.

To explain this behavior, the dynamic viscosity of rubber blends was investigated. From Figures 3 and 4, it becomes evident that the viscosity of BRblends is higher in comparison with the viscosity of NRblends with the corresponding ferrite content. The difference between the viscosities of equivalent NR and BRblends becomes larger with increasing content of magnetic filler. The viscosity of mixed rubber blends is very important factor playing the significant role when filler or fillers are dispersed in the rubber matrix. The higher viscosity of BRblends is likely responsible for the better dispersion of ferrite in the rubber matrix. For that reason also, the total surface of ferrite aggregates and agglomerates declined with doping content. The samples of BRblends with 20 and $40 \mathrm{phr}$ of ferrite were not subjected to experiments, because they were not possible to be processed into required test samples due to the soft rubber matrix.

From SEM images (Figure 5), it is seen a larger area of the phase interface between ferrite particles and butadiene rubber matrix (Figure 5(b)), therefore, it seems that the compatibility between ferrite and butadiene rubber is weaker than that of ferrite-natural rubber (Figure 5(a)), although the filler dispersion was found to be better in case of BRblends.

The values of the dispersion degree of ferrite and carbon black in natural rubber-based blends were also examined as shown in Figure 6. It becomes apparent that the best fillers dispersion degree exhibits the sample filled only with carbon black ( $85 \mathrm{phr}$ ) and the sample with $68 \mathrm{phr}$ of carbon black and $17 \mathrm{phr}$ of ferrite. With increasing content of ferrite (and decreasing content of carbon black), the fillers dispersion degree gradually decreases. Simultaneously, the total surface of fillers agglomerates and aggregates becomes larger with increasing of ferrite weight fraction although the total volume fraction of both fillers decreases (Figure 6).

The total values of the fillers dispersion degree of rubber blends filled with combinations of ferrite and carbon black are much higher in comparison with the values of the 


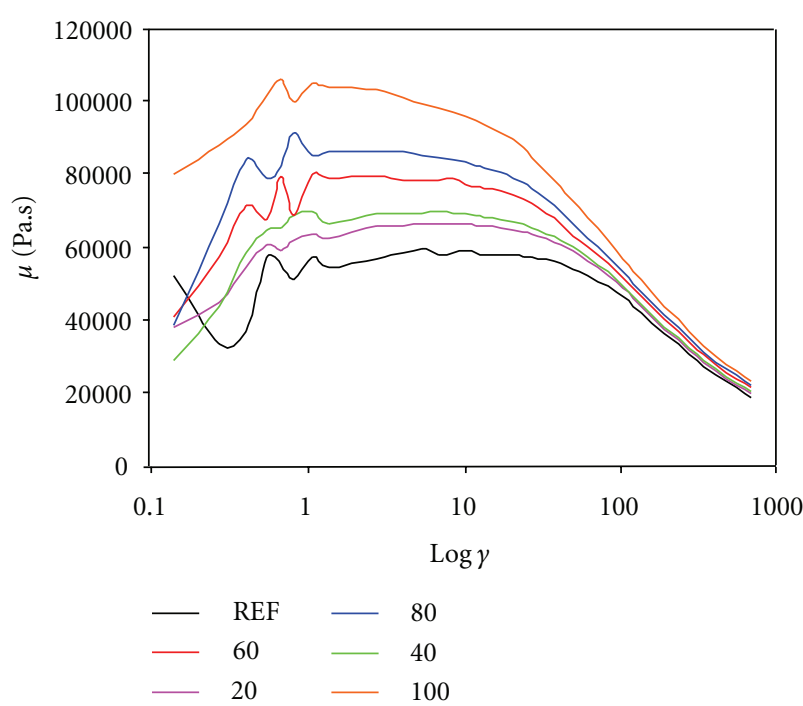

Figure 4: Dependence of dynamic viscosity $\mu$ of butadiene rubberbased blends filled with different content of ferrite on strain amplitude $\gamma$ at temperature $80^{\circ} \mathrm{C}$ and frequency $0.2 \mathrm{~Hz}$.

filler dispersion degree of ferrite-filled BR and NRrubber blends. These results to a certain extent correspond with some experimentally obtained results [7], which described that the rubber blend filled only with carbon black showed much more homogenous structure in comparison to the rubber blend filled only with ferrite, just as in our case (Figure 5(c)). This indicates very good compatibility and bonding between carbon black and the rubber. When some carbon black is added, the compatibility between ferrite and the rubber is improved. When more carbon black is added, magnetic particles are embedded in and well bound with the rubber matrix. The presence of carbon black in the rubber leads to significant increase of the viscosity of mixed rubber blend (Figure 7), what makes mixing process more efficient. The dispersion of filler in the rubber is then also improved. The improving of mixing process and the higher interactions between carbon black and the rubber probably positively affect also immixture and better dispersion of magnetic filler. The different degree of the fillers dispersion and the different homogeneity could be also caused by the different granulometry and specific surface area of applied fillers. The dispersion of filler is thus influenced by the chemical structure of the rubber as well as by the structure and the granulometry of the filler.

The values of physical-mechanical properties of prepared composites filled only with ferrite are shown in Figures 810. The presence of magnetic filler in natural rubber-based composites leads to the increase of hardness (from 33 ShA for the unfilled sample to $41 \mathrm{ShA}$ for the sample with maximum ferrite content). The reason for the increase of hardness is that the hardness of ferrite is bigger than that of natural rubber. Also ferrite particles can fill various cavities in the rubber matrix what causes the increase of hardness as well.

The values of moduli M100 and M300 exhibit almost linear growth with ferrite loading increasing. From Figure 8, it is possible to observe more than $70 \%$ increase of modulus M100 and almost 90\% increase of modulus M300 of the maximum ferrite-filled vulcanizate in comparison with corresponding values of M100 and M300 of the reference sample.

The elongation at break of NRcomposites by contrast showed the decreasing tendency in all ferrite concentration range (Figure 9). The change in tensile strength at break in dependence on the magnetic filler content is not very significant (Figure 9). One can see that the small maximum of the observed property is reached somewhere around medium ferrite contents (40-60 phr).

From Figure 10, it becomes evident that the tensile strength at break and the elongation at break of BRcomposites were found to increase with ferrite loading increasing. The hardness of BRcomposites was also improved in dependence on doping content (from $45 \mathrm{ShA}$ to $54 \mathrm{ShA}$ for the composite with maximum ferrite loading). The values of moduli were not possible to measure, because the vulcanizates were ruptured at deformation less than $100 \%$.

From the above-mentioned changes, it becomes evident that ferrite exhibits only a small reinforcing effect in rubber materials. But the degree of reinforcement is rather low even at the maximum ferrite content. The reason is attributed to the low filler dispersion degree and the small adhesion between the ferrite particles and the rubber with many voids existing between the two phases. The inner voids lead to stress concentration inside the sample, what may result in rupture at low stress. The possible reason of low reinforcing effect of applied magnetic filler is that ferrite particles tend to agglomerate. Therefore, the improvement of filler dispersion inside the rubber and the enhancement of adhesion between the rubber and the filler might be the way for the preparation of elastomeric magnetic composites with unique magnetic and elastic properties.

The hardness of both ferrite and carbon black-filled NRcomposites linearly decreases with increasing of ferrite weight fraction (from $68 \mathrm{ShA}$ for the composite filled only with carbon black to $42 \mathrm{ShA}$ for the composite filled only with ferrite). This is likely a consequence of the lowering of fillers volume fraction in rubber blends, because ferrite exhibits higher density when compared to the density of carbon black. The increasing content of magnetic filler in combinations with carbon black at the same mass content of both fillers leads to the decrease of fillers volume fraction.

The values of moduli M100 and M300 were found to significantly decrease with ferrite weight fraction increasing (Figure 11). The modulus M300 of the composite filled only with carbon black was not measured because the elongation of this sample did not reach $300 \%$.

From Figure 12, nonlinear increase of the tensile strength at break and the elongation at break with increasing of ferrite weight fraction were recorded.

The different character of physical-mechanical properties of composites filled with fillers combinations is attributed mainly to the reducing content of carbon black. As mentioned earlier, the presence of carbon black in the rubber matrix increases the viscosity of mixed rubber blend, which supports the filler infiltration process. As a result, carbon 


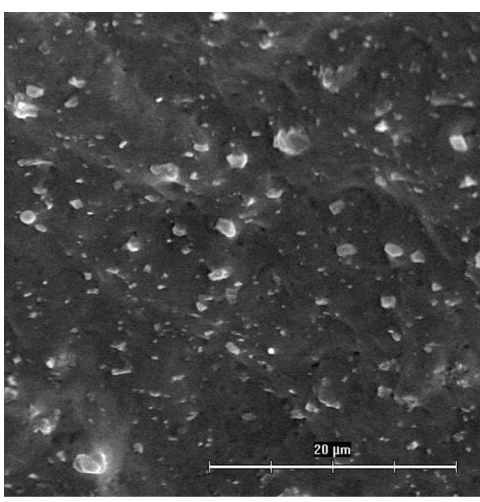

$20 \mathrm{phr}$

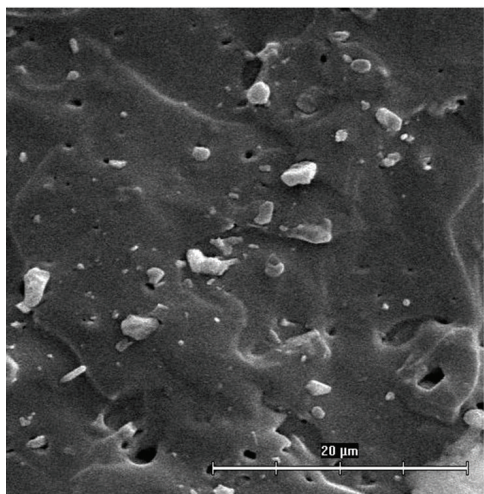

$20 \mathrm{phr}$

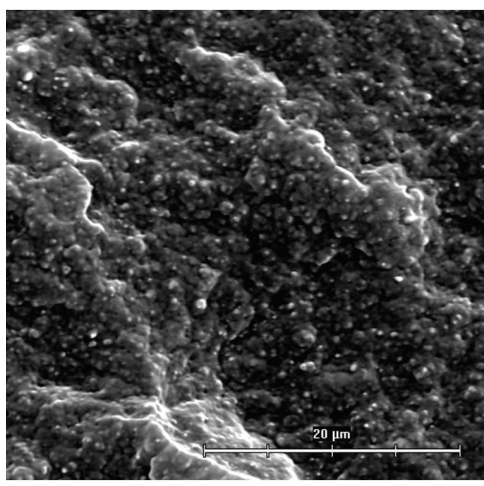

CB:F 5:0

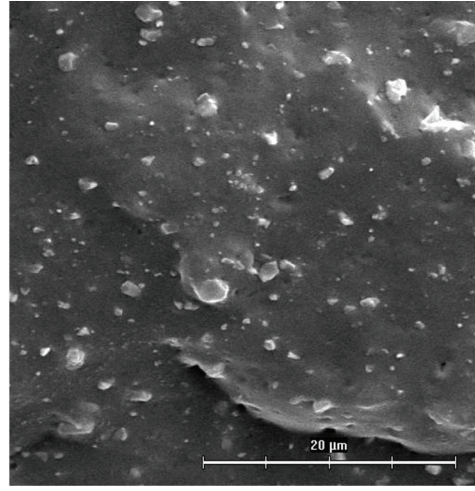

$60 \mathrm{phr}$

(a)

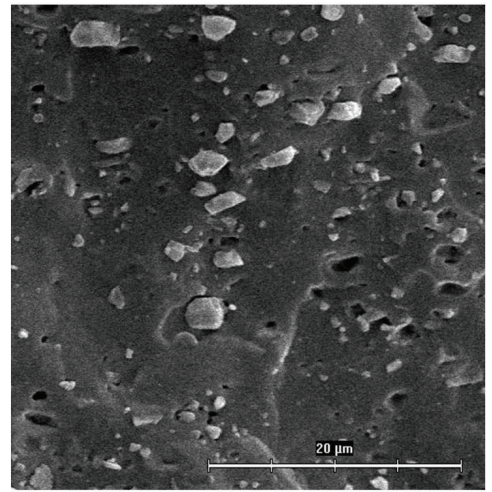

$60 \mathrm{phr}$

(b)

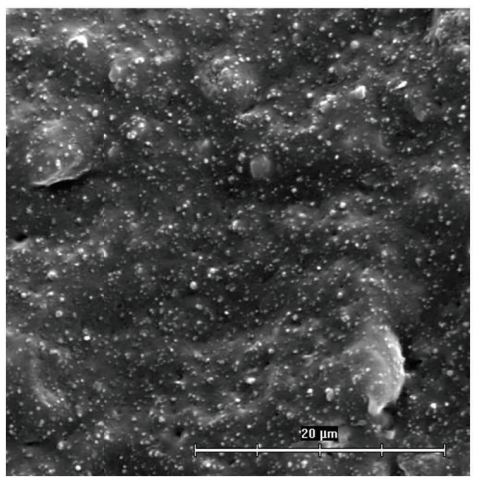

CB:F $1: 1$

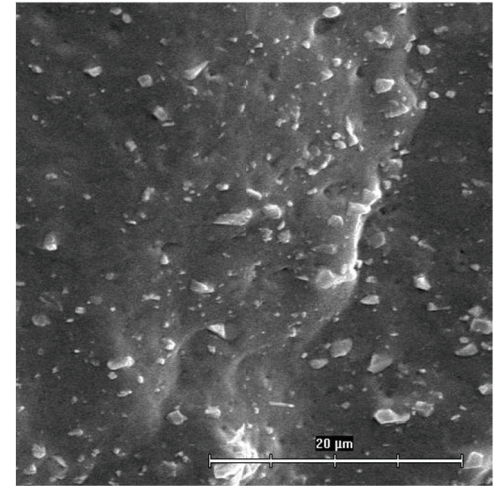

$100 \mathrm{phr}$

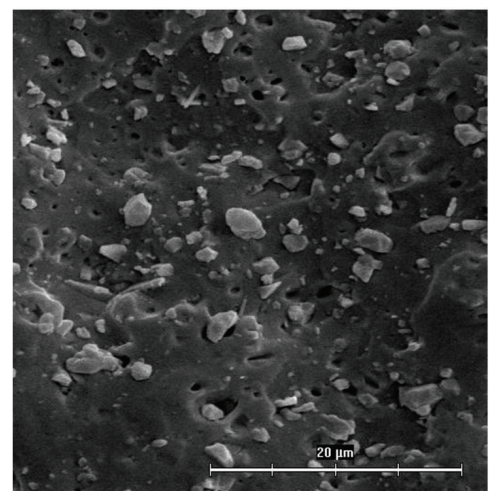

$100 \mathrm{phr}$

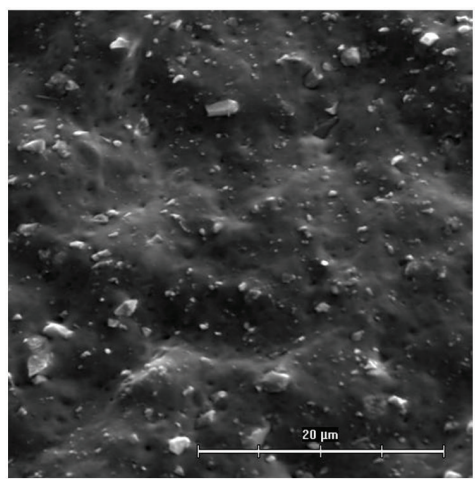

CB:F 0:5

(c)

FIGURE 5: SEM images of NR composites (a), BR composites filled with different ferrite content (b), and NR composites filled with fillers combinations (c).

black is well dispersed within the rubber, and the microhomogenous structure is formed. Due to very good adhesion and binding forces between carbon black and the rubber, the mobility of macromolecular chains is restricted, and the total reinforcement of the rubber matrix is then achieved. As a result, the improving of physical-mechanical properties of composites is possible to obtain. Therefore, the increase of tensile strength at break with decreasing content of carbon black in fillers combinations seems to be very remarkable and surprising. This behavior is still very hard to explain.

The remanent magnetic induction $B_{r}$ of ferrite-filled $\mathrm{NR}$ and BRcomposites shows significant increasing tendency with increasing content of magnetic filler (Figure 13). The difference between the values $B_{r}$ of NRcomposites with $20 \mathrm{phr}$ and $100 \mathrm{phr}$ of ferrite was more than $470 \%$. Sharp difference between the values $B_{r}$ of the sample with 


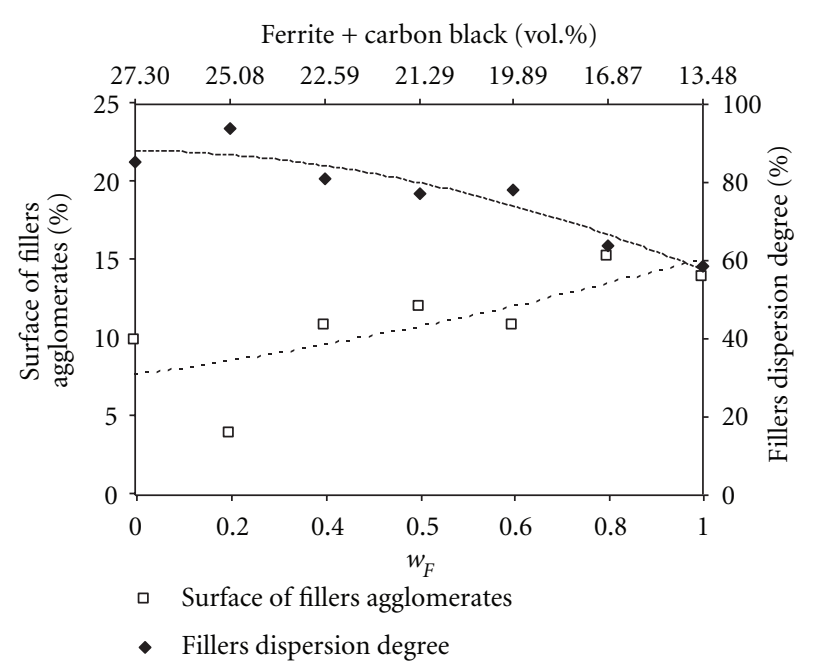

Figure 6: Influence of ferrite weight fraction on fillers dispersion degree and surface of fillers agglomerates in natural rubber-based blends filled with fillers combinations.

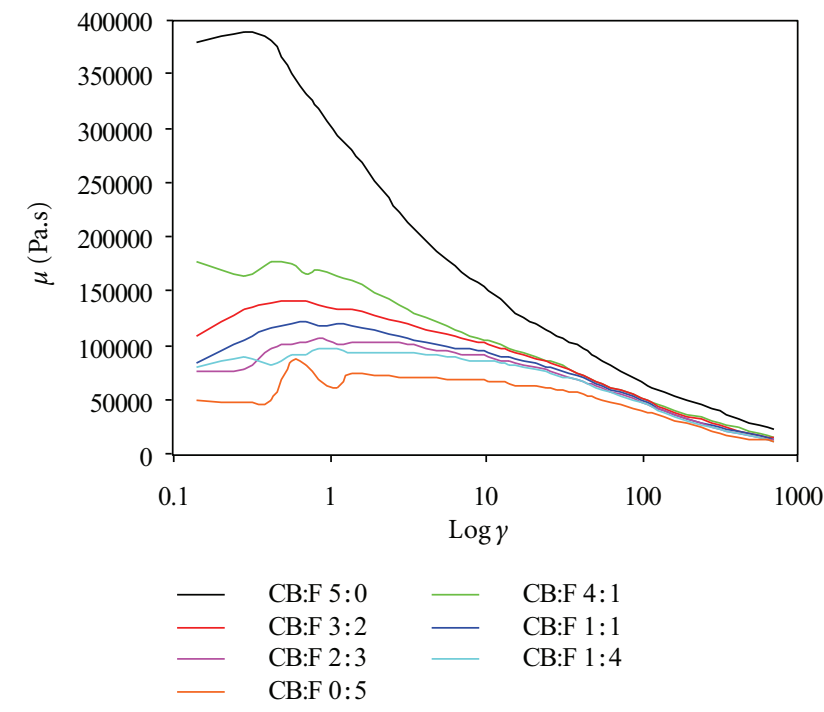

Figure 7: Dependence of dynamic viscosity $\mu$ of natural rubberbased blends filled with fillers combinations on strain amplitude $\gamma$ at temperature $80^{\circ} \mathrm{C}$ and frequency $0.2 \mathrm{~Hz}$.

maximum ferrite loading and the sample with minimum ferrite loading was recorded also in case of BRcomposites, approximately $180 \%$.

The increasing content of ferrite in combinations with carbon black leads also to the considerable enhancement of the remanent magnetic induction as seen in Figure 14. When we compare the values $B_{r}$ of composites filled with fillers combinations with the values $B_{r}$ of composites filled only with magnetic filler with approximately the same ferrite content, it was possible to observe the similar values of examined magnetic property. The obtained results revealed that the presence of carbon black in the rubber has no substantial influence on magnetic characteristics of prepared composites. The values of magnetic characteristics are

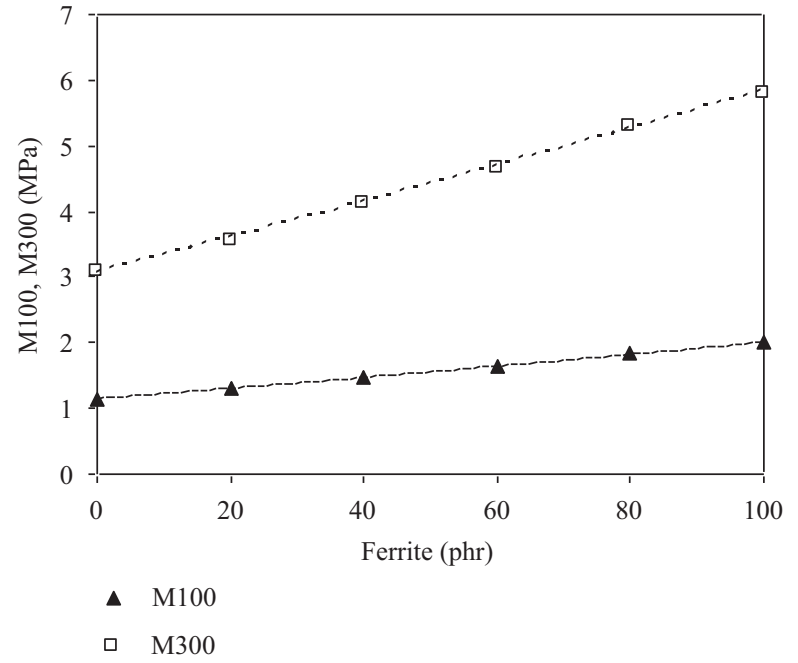

Figure 8: Influence of ferrite content on moduli M100 and M300 of natural rubber-based composites.

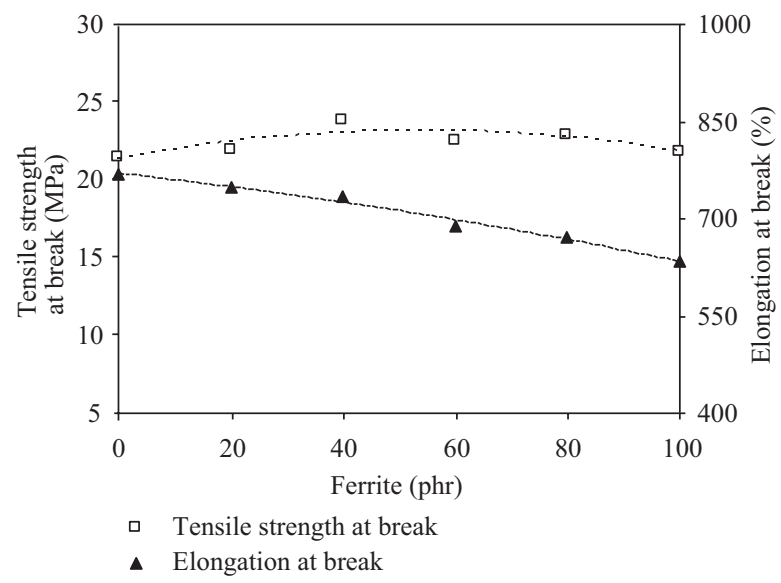

FIGURE 9: Influence of ferrite content on tensile strength at break and elongation at break of natural rubber-based composites.

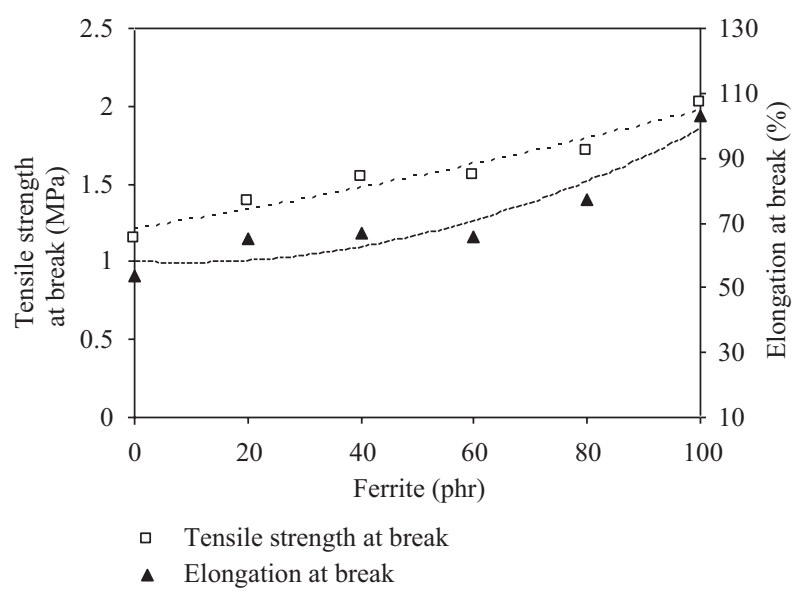

FIGURE 10: Influence of ferrite content on tensile strength at break and elongation at break of butadiene rubber-based composites. 


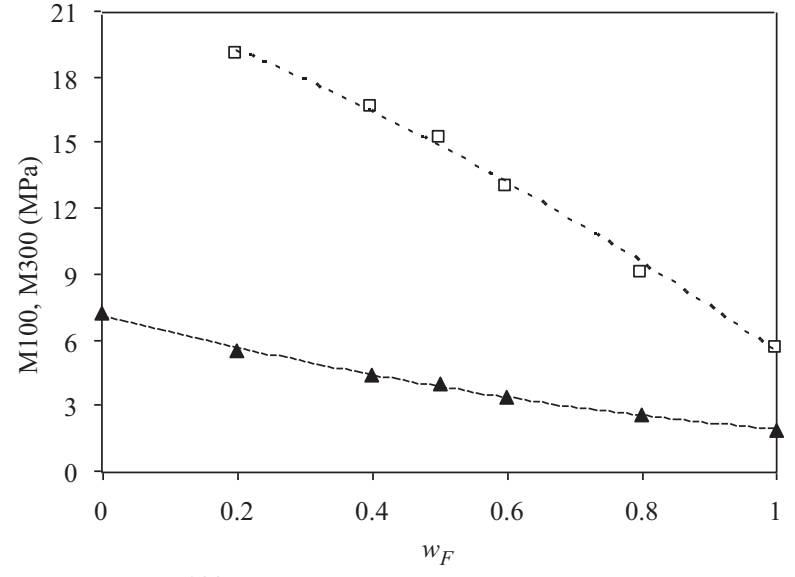

\ $\mathrm{M} 100$

口 $\mathrm{M} 300$

Figure 11: Influence of ferrite weight fraction on moduli M100 and M300 of natural rubber-based composites filled with fillers combinations.

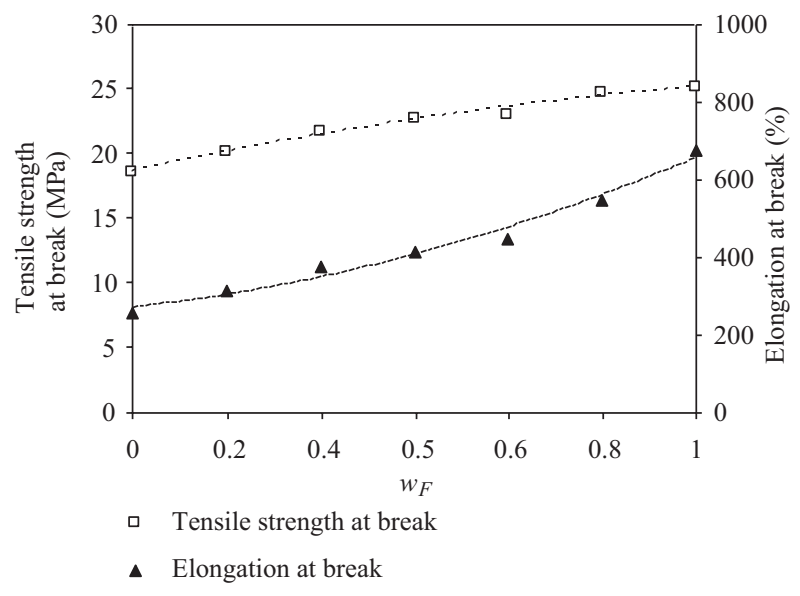

FIGURE 12: Influence of ferrite weight fraction on tensile strength at break and elongation at break of natural rubber-based composites filled with fillers combinations.

dependent only on the amount of applied magnetic filler regardless of the reinforcing filler present in the rubber.

The results achieved by the study of magnetic characteristics demonstrate that the more ferrite rubber compounds contain, the better are magnetic properties of composites even in case of carbon black incorporated. This should be taken into consideration when preparing elastomeric materials filled with magnetic fillers. Depending on the required applications, the final properties of such materials could be achieved not only by incorporation of magnetic filler, but also by incorporation of other filler or fillers, which might be able to provide desired attributes of those systems, without any negative influence on magnetic characteristics.

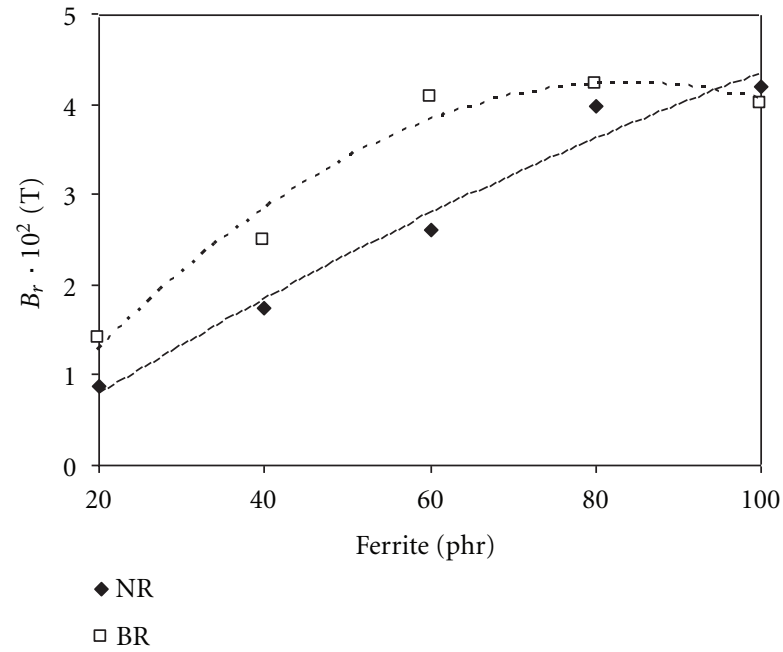

Figure 13: Influence of ferrite content on remanent magnetic induction $B_{r}$ of natural and butadiene rubber-based composites.

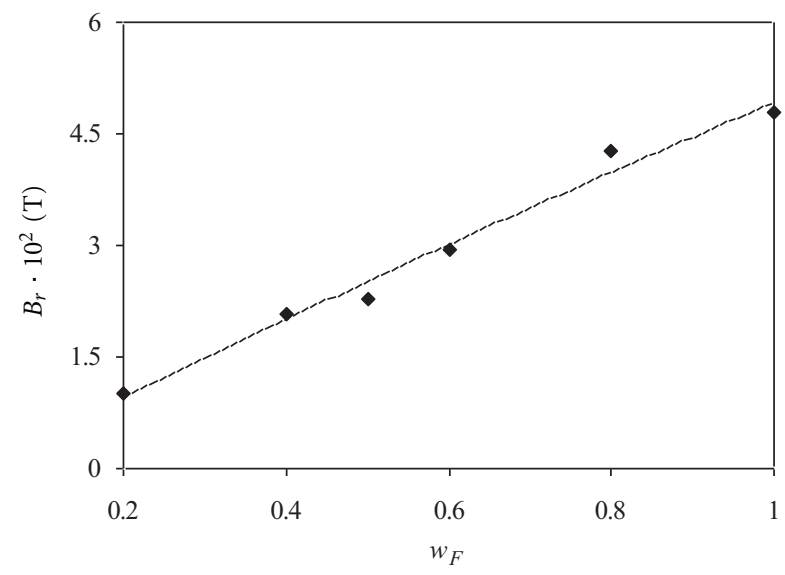

Figure 14: Influence of ferrite weight fraction on remanent magnetic induction $B_{r}$ of natural rubber-based composites filled with fillers combinations.

\section{Conclusion}

The aim of the work was to evaluate the filler dispersion degree in the rubber blends filled with ferrite as well as in the rubber blends filled with combinations of ferrite and carbon black. Physical-mechanical and magnetic properties of prepared composites were then investigated. The results showed that the ferrite dispersion degree in the rubber matrices increases with doping content of filler, but despite of that it is quite low. The addition of carbon black increases the viscosity of mixed rubber blends, what support the filler infiltration process, and thus also the dispersion of magnetic filler in the rubber matrix is enhanced, and more homogenous structure is formed. Ferrite in the rubber matrices exhibits only low reinforcing effect, but in case of composites filled with combinations of ferrite and carbon black, the tensile strength at break was found to increase with increasing content of ferrite in fillers combinations. Although the 
mechanism of the interactions between carbon black and ferrite particles is still not very clear, the microstructure and physical-mechanical properties can be positively influenced by the change in fillers combinations.

\section{Acknowledgment}

This work was supported by Grant Agency VEGA, project no. 1/1163/12.

\section{References}

[1] S. Borros and N. Dishovsky, "Hard magnetic fillers influence on the natural rubber vulcanization process," Kautschuk und Gummi Kunststoffe, vol. 57, no. 1-2, pp. 43-47, 2004.

[2] E. Ürögiová, I. Hudec, D. Bellušová, and P. Šuri, "Structure and properties of rubber blends with ferromagnetic fillers," Polymers for Advanced Technologies, vol. 18, no. 2, pp. 128-134, 2007.

[3] G. Diguet, E. Beaugnon, and J. Y. Cavaillé, "Shape effect in the magnetostriction of ferromagnetic composite," Journal of Magnetism and Magnetic Materials, vol. 322, no. 21, pp. 33373341, 2010.

[4] J. Kruželák, R. Szabová, D. Belluǎová, G. Kyselá, and I. Hudec, "Elastomeric materials with magnetic fillers for intelligent tyres construction," Kautschuk Gummi Kunststoffe, vol. 63, no. 1-2, pp. 20-24, 2010.

[5] P. Alexy, Processing of Polymers, Slovak University of Technology, Bratislava, Slovakia, 2011.

[6] H. H. Le, S. Ilisch, G. R. Kasaliwal, and H. J. Radusch, "Filler phase distribution in rubber blends characterized by thermogravimetric analysis of the rubber-filler gel," Rubber Chemistry and Technology, vol. 81, no. 5, pp. 767-781, 2008.

[7] L. Chen, X. L. Gong, and W. H. Li, "Effect of carbon black on the mechanical performances of magnetorheological elastomers," Polymer Testing, vol. 27, no. 3, pp. 340-345, 2008. 

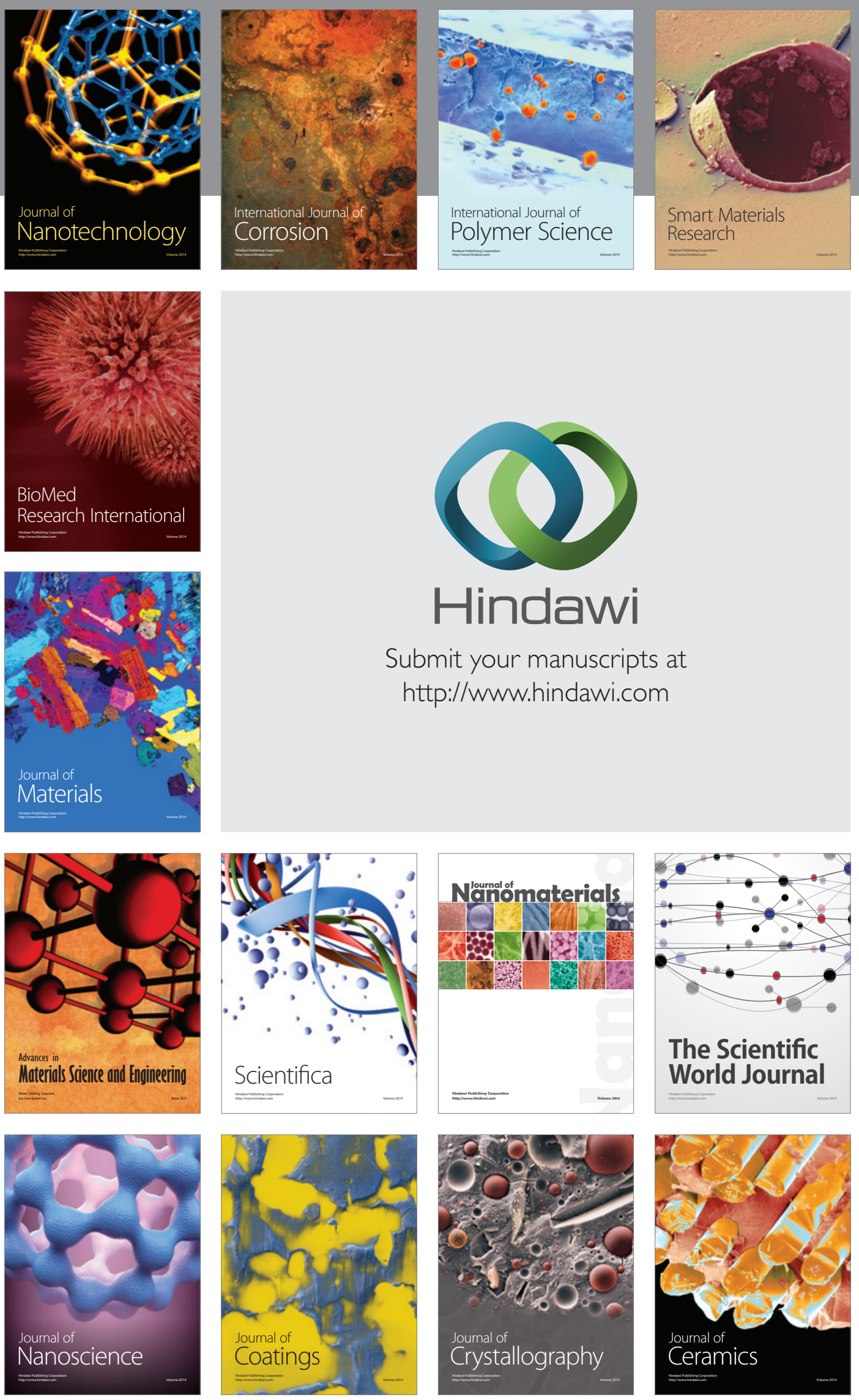

The Scientific World Journal

Submit your manuscripts at

http://www.hindawi.com

\section{World Journal}

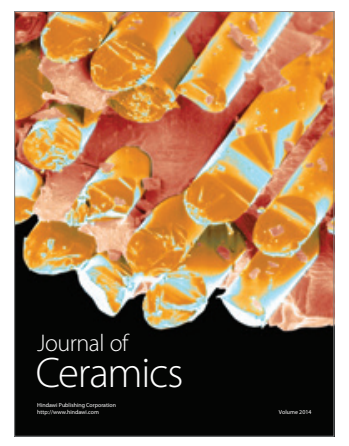

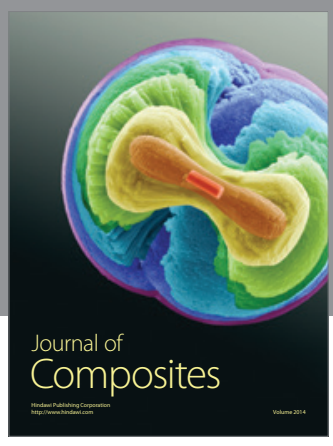
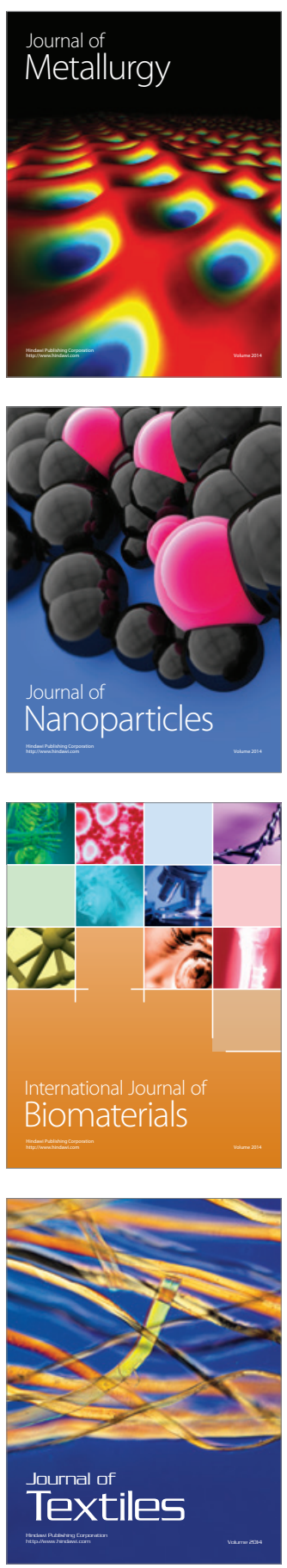